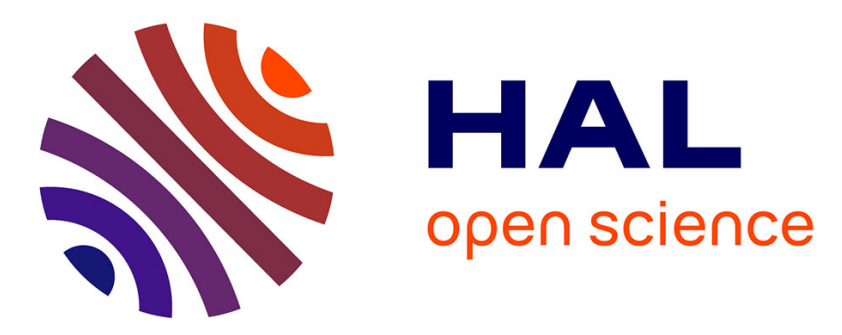

\title{
Characterization of the spectral signature of dual-fuel combustion luminosity: implications for evaluation of natural luminosity imaging
}

\author{
Aleš Srna, Rolf Bombach, Kai Herrmann, Gilles Bruneaux
}

\section{To cite this version:}

Aleš Srna, Rolf Bombach, Kai Herrmann, Gilles Bruneaux. Characterization of the spectral signature of dual-fuel combustion luminosity: implications for evaluation of natural luminosity imaging. Applied Physics B - Laser and Optics, 2019, 125 (7), 10.1007/s00340-019-7222-z . hal-02264874

\section{HAL Id: hal-02264874 \\ https://hal-ifp.archives-ouvertes.fr/hal-02264874}

Submitted on 7 Aug 2019

HAL is a multi-disciplinary open access archive for the deposit and dissemination of scientific research documents, whether they are published or not. The documents may come from teaching and research institutions in France or abroad, or from public or private research centers.
L'archive ouverte pluridisciplinaire HAL, est destinée au dépôt et à la diffusion de documents scientifiques de niveau recherche, publiés ou non, émanant des établissements d'enseignement et de recherche français ou étrangers, des laboratoires publics ou privés. 


\title{
Title
}

Characterization of the Spectral Signature of Dual-Fuel Combustion Luminosity: Implications for Evaluation of Natural Luminosity Imaging

\section{Authors:}

- Ales Srna, Paul Scherrer Institute, OVGA 119A, CH-5232 Villigen PSI, Switzerland

- Email: ales.smaciopsi.ch: Tel.; +417931087 74, Fax: +41563102624

- Rolf Bombach, Paul Scherrer Institute, OVGA 107, CH-5232 Villigen PSI, Switzerland

- Kai Herrmann, Institute of Thermal and Fluid Engineering, School of Engineering, University of Applied Sciences Northwestern Switzerland, Klosterzelgstrasse 2, CH-5210 Windisch, Switzerland

- Gilles Bruneaux, IFP Energies nouvelles, 1 et 4 avenue de Bois Préau, 92852 Rueil-Malmaison, France; Institut Carnot IFPEN Transports Energie

\begin{abstract}
$\mathrm{N}$-dodecane pilot-ignited lean-premixed natural-gas combustion has been investigated in a rapid compression-expansion machine. The aim of this study was to characterize the combustion spectral footprint; identify the main sources of natural luminosity, characterize the temporal brightness evolution, and provide guidance for the evaluation of natural luminosity imaging acquisitions. Natural luminosity spectra in the range of $280-610 \mathrm{~nm}$ were acquired, 1D-resolved along the injector axis, using an imaging spectrograph and intensified high-speed camera. Four significant contributions to the natural luminosity were identified: Soot, $\mathrm{OH}^{*}$ and $\mathrm{CH}^{*}$ chemiluminescence, as well as overlapping broadband chemiluminescence of $\mathrm{CO}_{2}{ }^{*}$, $\mathrm{CHO}^{*}$ and $\mathrm{CH}_{2} \mathrm{O}^{*}$ species. The $\mathrm{CH}^{*}$ chemiluminescence could be only detected at ignition and during the pilot-fuel combustion period. Similarly, initial $\mathrm{OH}^{*}$ and broadband luminosity were also detected at ignition. However, this luminosity additionally increased late in the cycle, when methane, enriched with diluted pilot-fuel, forms an extensive burnt zone with close-to-stoichiometry conditions. For the ignition delay detection, imaging of broadband luminosity has to be recommended since at ignition it shows a higher rise-rate than the $\mathrm{OH}^{*}$ chemiluminescence. It was shown that, after ignition, in dual-fuel combustion, the coupling between the nutural luminosity and heat release-rate is too weak to extract useful information.
\end{abstract}

\section{Introduction}

The optical investigations of combustion often rely on the imaging of flame natural luminosity. Such detection is state of the art and utilizes flame imaging in various wavelength ranges: around $310 \mathrm{~nm}$ for $\mathrm{OH}^{*}$ chemiluminescence detection, around $430 \mathrm{~nm}$ for the detection of $\mathrm{CH}^{*}$; or broadband/color imaging for the detection of all luminescent species in the flame. Nevertheless, the chemiluminescence of all species in flames strongly depends on the temperature, reaction rates, equivalence ratio, pressure as well as the strain rate. Furthermore, such imaging is prone to the interference by soot incandescence. When combustion processes are investigated optically, a study of the spectral signature of combustion is of high value to identify possible interferences as well as to establish a framework for the interpretation of results. During the validation of (FD) studies often $\mathrm{CH}^{*}$ or $\mathrm{OH}^{*}$ chemical mechanisms are used to predict the chemiluminescence signal. For comparison with experiments, it is of paramount importance that the experiments indeed detect only the target species emission.

The natural tlame luminosity originates from the emission of several species emitting in a wide range of wavelengths. In sparkignited premixed-combustion engines, several studies investigated the flame and spark-plasma spectra [1]. Within the variety of combustion concepts featuring auto-ignition, the spectral footprint of non-sooting Homogeneous-Charge CompressionIgnition $(\mathrm{HCCl})$ is most thoroughly investigated. In the visible range, studies report broadband chemiluminescence between $300 \mathrm{~nm}-600 \mathrm{~nm}$ to be the primary emission source [2-6]. Additionally, the chemiluminescence of $\mathrm{CH}^{*}$ and $\mathrm{OH}^{*}$ becomes visible at sufficiently high equivalence ratio $[4,5]$. The ratio of $\mathrm{CH}^{*} / \mathrm{OH}^{*}$ as well as the intensity of the broadband (BB) luminosity, were shown to correlate well with the local equivalence ratio, and both, the $\mathrm{OH}^{*}$ and $\mathrm{BB}$ signals were found to be proportional to the Heat Release Rate (HRR) [2]. With increasing level of spatial mixture stratification. the combustion regime 
changes to partially premixed combustion until the conventional diesel combustion regime is reached. At diffusion combustion stage, soot becomes the dominant source of luminosity at longer wavelengths $[2,7-9]$. Nevertheless, at shorter wavelengths, a considerable portion of luminosity still originates from $\mathrm{OH}^{*}, \mathrm{CH}^{*}$ and $\mathrm{BB}$ luminosity. During the autoignition and premixed burning part, $\mathrm{BB}$ contributions from both, $\mathrm{CO}_{2}{ }^{*}$ as well as $\mathrm{CH}_{2} \mathrm{O}^{*}$ and $\mathrm{CHO}^{*}$ chemiluminescence were identified, while at later stages the $\mathrm{BB}$ luminosity is again dominated by $\mathrm{CO}_{2}{ }^{*}[7,8]$. The proportionality of HRR and $\mathrm{OH} / \mathrm{BB}$ intensity does not apply anymore.

The chemical mechanisms describing the formation of the excited luminescing species can aid the understanding of the experimentally observed trends. A short review of the literature suggests the different chemiluminescent species to be produced at different reaction stages during the combustion. First. excited $\mathrm{CH}^{*}$. originating from the oxidation reactions of two-carbon-atom species, is expected to form $[10,11]$. Therefore, considerably stronger $\mathrm{CH}^{*}$ chemiluminescence in flames of higher hydrocarbons is expected relative to methane. $\mathrm{Next}, \mathrm{CH}_{2} \mathrm{O}$ and $\mathrm{CHO}$ species will be formed. Literature investigating these particular species chemiluminescence is scarce. $\mathrm{CH}_{2} \mathrm{O}^{*}$ is suggested to be formed in the recombination reactions of $1-$ carbon atom radicals $[12,13]$ and $\mathrm{CHO}^{*}$ during the oxidation reactions of $\mathrm{CH}_{2} \mathrm{O}$ with the $\mathrm{OH}$ radical [13,12]. At last, the formation of $\mathrm{CO}_{2}{ }^{*}$ and $\mathrm{OH}^{*}$ species is expected. $\mathrm{CO}_{2}{ }^{*}$ is formed mostly through the oxidation of $\mathrm{CO}$ with $\mathrm{O}$ atoms, while the $\mathrm{OH}^{*}$ originates from the recombination reactions of $\mathrm{H}$ and $\mathrm{O}$ atoms as well as from the oxidation of $\mathrm{CH}$ radical with $\mathrm{O}_{2}$ $[13,14,10,15]$. Contrary to $\mathrm{CH}^{*}, \mathrm{CHO}^{*}$, and $\mathrm{CH}_{2} \mathrm{O}^{*}$, which are abundant only during the combustion, the $\mathrm{CO}+\mathrm{O} \rightarrow \mathrm{CO}_{2}{ }^{*}$ and $\mathrm{O}+\mathrm{H} \rightarrow \mathrm{OH}^{*}$ reactions remain active also in the hot burnt zones with close to stoichiometric conditions $[13,14]$. This leads to a persistent $\mathrm{CO}_{2}^{*}$ and $\mathrm{OH}^{*}$ luminosity also in the burnt regions.

The dual-fuel combustion process comprises of pilot-fuel auto-ignition in methane/air mixture, followed by turbulent premixed flame propagation through the remaining charge. The fuel equivalence ratio, as well as the ratio of premixed fuel and pilotfuel, is strongly stratified in the combustion chamber. Several optical studies investigated this combustion using chemiluminescence and schlieren imaging |16-21]. The common observation is that methane strongly defers the ignition delay, and during the pilot-fuel combustion a higher HRR is observed due to the simultaneous combustion of premixed methane.

The motivation for this study was the observation of a decoupled evolution of HRR and $\mathrm{OH}^{*}$ brightness, perceived in our previous work [16,17] and other studies [19]. Figure 1 illustrates the combustion HRR rate compared to the field-of-view integrated $\mathrm{OH}^{*}$ chemiluminescence for a sweep of background methane equivalence ratios in the RCEM [16]. Adding methane into the charge air leads to an increased peak HRR (by a factor up to 2) relative to the pilot-fuel-only case. The $\mathrm{OH}^{*}$ chemiluminescence signal appears to be decoupled from the HRR. In dual-fuel cases, the highest $\mathrm{OH}^{*}$ chemiluminescence signal has been detected during the premixed flame propagation stage (1-2 $\mathrm{ms}$ after ignition) and up to 10 times higher $\mathrm{OH}^{*}$ signals were observed for higher methane background concentrations. This behavior has also been reported by Schlatter et al. [19] for $n$-heptane pilot fuel. Up to date, it was not investigated whether this signal originates from $O H^{*}, B^{3}$ chemiluminescence or possibly soot black-body radiation.

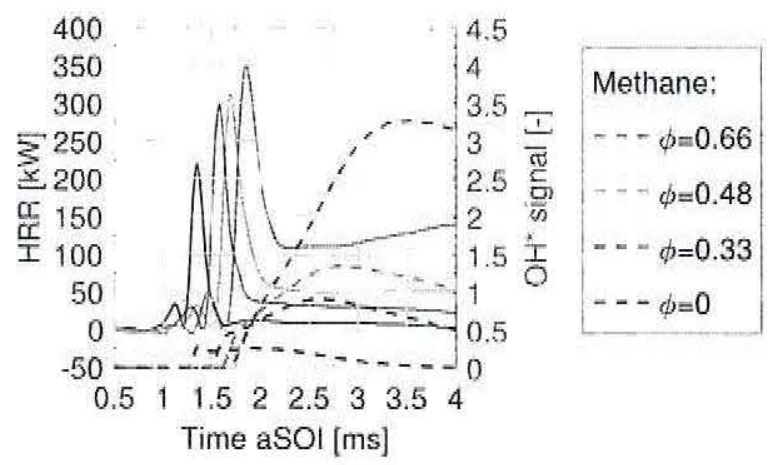

Figure 1: Combustion HRR (full-line) und field-of-view infegrated OII" imaging signal (dashed) for a variation of premixed methane equivalence ratio, acquired using the Iest setup from [16]. Conditions: $\mathrm{T}_{\$ 01}=810 \mathrm{~K}, \mathrm{p}_{\mathrm{s} 01}=25$ har. injection duration: $0.58 \mathrm{~ms}$, injection pressure; 600 bar, pilot-liucl: n-ilodecanc. 
Figure 1 indicates a considerably slower rise rate of $\mathrm{OH}^{*}$ signal at ignition in dual-fuel cases. This dependence of the intensity and temporal evolution of the $\mathrm{OH}^{*}$ chemiluminescence might have a strong implication on the detection of ignition delay using a thresholding approach. Similar might also apply for the general natural luminosity imaging. The correlation between the local ignition and chemiluminescence is presented in Figure 2 by comparing the simultaneously acquired schlieren and $\mathrm{OH}^{*}$ images from diesel and dual-fuel case with the same ignition delay. The optical system sensitivity was unchanged [17]. At ignition. the first $\mathrm{OH}^{*}$ signal is expected to be detected. The temporal evolution of the Schlieren signal is more complex [22]: in the diesel case, first schlieren signals with high contrast are detected in the fuel-vapor zones due to the evaporative cooling. The low-temperature combustion generated heat compensates for the evaporative cooling and leads to a softening of the schlieren signal, which then reappears after ignition.
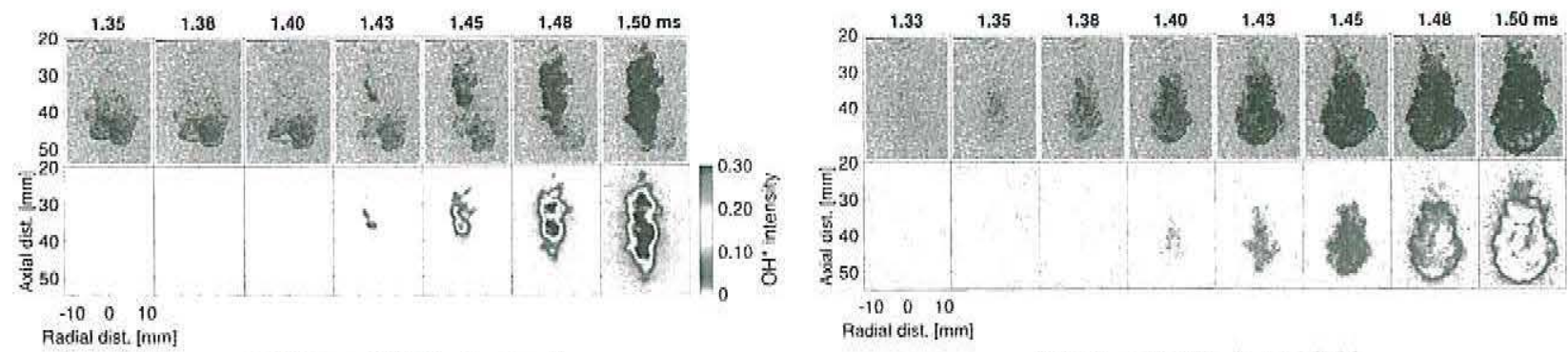

(a) $\mathrm{T}_{\mathrm{SOI}}=770 \mathrm{~K}, \phi_{\mathrm{CH} 4}=0$

(b) $\mathrm{T}_{\text {SOI }}=850 \mathrm{~K}, \phi_{\mathrm{CH}-4}=0.66$

Figure 2: Time-series of schlieren and $\mathrm{OH}^{*}$ chemiluminescence images for (a) diesel, and (b) dual-fuel case with approximately the same ignition delay,

In the diesel case (Figure 2a), the first appearance of the $\mathrm{OH}^{*}$ signal $(1.06 \mathrm{~ms})$ correlates well with the first schlieren signal reappearance upstream of the spray tip. The $\mathrm{OH}^{*}$ intensity quickly rises and exceeds $30 \%$ of the camera dynamic-range already $50 \mu \mathrm{s}$ after ignition. In contrast, the dual-fuel case shows a very slow rise of $\mathrm{OH}^{*}$ signal. First photons are visible on the $\mathrm{OH}^{*}$ images at $1.02 \mathrm{~ms}$ after the start of injection. It takes more than $125 \mu$ s to reach the intensity comparable to $30 \%$ of the camera dynamic-range used in the diesel case. Schlieren imaging is more sensitive to detect ignition in the dual-fuel case the first schlieren signal reappears already 1-2 image frames prior to the first $\mathrm{OH}^{*}$ photons being detected $(0.99 \mathrm{~ms})$ This is considerably earlier than the ignition delay $(1.06 \mathrm{~ms})$ detected by the common thresholding technique used in [16]. Depending on the sensitivity of the employed detection system, the slow rise rate of the $\mathrm{OH}^{*}$ signal can lead to significant overprediction of the ignition delay, as reported in [19].

Observing the peculiarity of ignition detection in dual-fuel cases, the objectives of the present investigations were: (1) characterize the dual-fuel combustion natural luminosity relative to the luminosity of conventional diesel combustion, (2) identify the species contributions to the natural luminosity, (3) explain the observed temporal evolution of $\mathrm{OH}^{*}$ signal intensity, and (4) provide guidelines for the evaluation of dual-fuel natural luminosity imaging.

This publication is structured as follows: First, the experimental test rig, the ID-spectroscopy setup for the time-resolved acquisition of flame-luminosity spectra, as well as the processing approach, are presented. In the results section, the species contributing to the natural luminosity were identified, and the dependence of spectral emission on the charge and injection conditions is presented. The discussion focuses on the implications of the observed luminosity trends for the evaluation of natural luminosity imaging in the dual-fuel combustion investigations.

\section{Experimental Apparatus}

\subsection{Rapid Compression-Expansion Machine (RCEM)}

The Rapid Compression Expansion Machine (RCEM) used in this study is a free-floating piston machine with a bore of $84 \mathrm{~mm}$ and stroke of up to $249 \mathrm{~mm}$. Methane-air mixture is conditioned in the combustion chamber prior to the rapid compression, and the mixture is ignited with a pilot injection initiated when the combustion chamber pressure reaches the set 
threshold level $\left(\mathrm{p}_{\text {sol }}\right)$. To admit the pilot fuel, a single-hole coaxial diesel injector with a $100 \mu \mathrm{m}$ conical nozzle is used, mounted at the cylinder periphery, with the injector axis in the radial direction relative to the RCEM cylinder axis. Readers interested in the detailed information on the RCEM combustion chamber geometry are referred to [17]. The detailed description of the RCEM operation principle and strategy are available in [23].

\subsection{Experimental conditions}

In this study, the RCEM has been operated at the maximal BDC displacement setting $\left(1,38 \mathrm{dm}^{3}\right.$ displacement, $249 \mathrm{~mm}$ BDC clearance to the cylinder head) to have a sufficient TDC clearance for minimizing the pilot spray interaction with walls. The operation strategy of the RCEM was selected based on previous operation experience to assure high-repeatability of the conditions at Start Of Injection (SOI): A mixture of methane and air with a BDC pressure of 1.2 bar has been conditioned in the cylinder before the rapid compression to assure homogeneous mixture [17]. The machine was operated at a compression ratio of about 20, and the pilot fuel injected early in the cycle (ca. $3.5 \mathrm{~ms}$ before TDC) when the cylinder pressure reached a threshold of 25 bar. The bulk charge temperature at ignition was controlled by adapting the cylinder head and walls temperature at the $\mathrm{BDC}$. Consequently, the $\mathrm{BDC}$ charge temperature (equal to the wall temperature [24]) and the temperature at the $\mathrm{SOI}\left(\mathrm{T}_{\text {sol }}\right)$ were changed.

The measurement matrix consisted of four main variations: Variation of the premixed methane equivalence ratio $\left(\phi_{\mathrm{CH} 4}\right)$ in the range between $0-0.66$, variation of $\mathrm{T}_{\mathrm{Sol}}(770 \mathrm{~K}, 810 \mathrm{~K}, 850 \mathrm{~K})$, variation of pilot injection duration $(0.38 \mathrm{~ms}, 0.58 \mathrm{~ms}$, $1.21 \mathrm{~ms})$ as well as the charge oxygen content ( $15 \%$, achieved by dilution of air with nitrogen.). The injection pressure was kept constant at 600 bar (steady fuel injection rate: $2.43 \mathrm{mg} / \mathrm{ms}$ ). Table 1 summarizes the experimental matrix and conditions of this study.

Table 1: Overview of the experimental matric. Values in braces were not acquired for all cross-variations. The values of the standard case are printed bold.

\begin{tabular}{|c|c|c|c|}
\hline & $\mathrm{T}_{\mathrm{SOI}}$ and $\phi_{\mathrm{CH} 4}$ variation & $\begin{array}{l}\text { Injection duration } \\
\text { variation }\end{array}$ & Charge oxygen variation \\
\hline Charge BDC pressure & \multicolumn{3}{|c|}{$1.20 \mathrm{bar}$} \\
\hline Stroke & \multicolumn{3}{|c|}{$236.5 \mathrm{~mm} \pm I \mathrm{~mm}$} \\
\hline Compression ratio & \multicolumn{3}{|c|}{20} \\
\hline BDC temperature & $343 \mathrm{~K}, 363 \mathrm{~K}, 383 \mathrm{~K}$ & \multicolumn{2}{|c|}{$363 \mathrm{~K}$} \\
\hline Pressure at $\mathrm{SOI}$ & \multicolumn{3}{|c|}{25 bar } \\
\hline Temperature at SOI ( $\left.\mathrm{T}_{\text {sol }}\right)$ & $770 \mathrm{~K}, 810 \mathrm{~K}, 850 \mathrm{~K}$ & \multicolumn{2}{|c|}{$810 \mathrm{~K}$} \\
\hline Charge oxygen content & \multicolumn{2}{|c|}{$21 \%$} & $15 \%$ \\
\hline $\begin{array}{l}\text { Premixed methane } \\
\text { equivalence ratio }\left(\phi_{\mathrm{CH}_{4}}\right)\end{array}$ & $\begin{array}{c}0,0.33,(0.48),(0.53) \\
0.59,(0.66)\end{array}$ & $0,0.33,0.59$ & $\begin{array}{c}0,0.33,0.59 \\
\text { (relative to } 21 \% \text { oxygen) }\end{array}$ \\
\hline Pilot injection duration & $0.58 \mathrm{~ms}$ & $\begin{array}{c}0.38 \mathrm{~ms}, 0.58 \mathrm{~ms} \\
1.21 \mathrm{~ms}\end{array}$ & $0.58 \mathrm{~ms}$ \\
\hline Pilot-fuel mass per injection & $1.18 \mathrm{mg}$ & $\begin{array}{c}0.64 \mathrm{mg} .1 .18 \mathrm{mg}, \\
2.67 \mathrm{mg}\end{array}$ & $1.18 \mathrm{mg}$ \\
\hline $\begin{array}{l}\text { Pilot injector energizing time } \\
\text { (ET) }\end{array}$ & $400 \mu \mathrm{s}$ & $300 \mu \mathrm{s}, 400 \mu \mathrm{s}, 700 \mu \mathrm{s}$ & $400 \mu \mathrm{s}$ \\
\hline Pilot injection pressure & \multicolumn{3}{|c|}{600 bar } \\
\hline
\end{tabular}

\subsection{Optical setup}

Two different sets of optical diagnostics were used in this study. The introduction ligures and Figure 9 present results acquired with a simultaneous Schlieren and $\mathrm{OH}^{*}$ chemiluminescence imaging setup described in [17]. Since both techniques represent state of the art, they are not further introduced here. Second, the combustion spectral footprint was characterized with a IDspectroscopy setup described below.

Figure 3 presents the 1D-spectroscopy setup employed to investigate combustion luminosity spectra. Emission was acquired through the piston window over two UV aluminum mirrors. A part of emitted light was reflected by the dichroic beamsplitter 
towards the spectrograph and projected on the spectrograph slit using an UV objective (Sodern Cerco $94 \mathrm{~mm} \mathrm{f} / 4.1$ ). The application of an imaging spectrograph (Acton SP-300i. grating 300 lines per mm, blazed for $500 \mathrm{~nm}$ ) enabled ID resolution of the spectrum along the slit. The spectrally dispersed light was detected with an intensified high-speed camera system (LaVision HS-IRO coupled with Photron FastCam SA1.1) operated at a frame rate of $20 \mathrm{kHz}$ (intensifier gate $45 \mu \mathrm{s}$ ). A slit with of $100 \mu \mathrm{m}$ was used, reduced to $40 \mu \mathrm{m}$ for strongly sooting cases, and the intensifier gain was adapted hetween $7-$ 20 counts/photoelectron depending on the flame brightness to fully exploit the camera dynamic-range. The wavelength range between $250-600 \mathrm{~nm}$ was acquired. Below $300 \mathrm{~nm}$ only weak radiation was detected, and therefore, separation of different grating orders was not necessary. The spectral resolution of about $2 \mathrm{~nm}$ and the resolution along the slit of about $1 \mathrm{~mm}$ were limited by the spectrograph aberrations and not by the camera resolution. The field of view of the ID spectroscopy was set to spectrally resolve the flame emission and soot luminosity in one dimension along the pilot-injector axis.

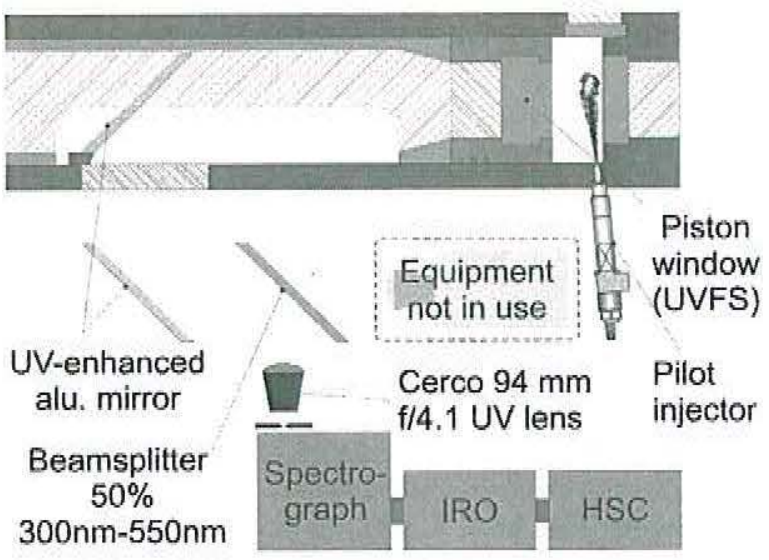

Figure 3: Optical setup for (1)-spectroscopy acquisitions at the RCEM, A rough sleteh of the RCEM geonetry and optical access is shown as well.

\subsection{Spectra processing}

Spectral images were processed to extract the spectra and identify the contributing species. First, the images were averaged over 10 experimental repetitions, and across 10 pixels along the axial direction (corresponding to $2 \mathrm{~mm}$ ). The so obtained raw spectra were further processed as demonstrated in Figure 4.

The raw spectra were corrected for the system spectral and spatial dependence of transmission and quantum efficiency (more detailed description in [17]). In the next stage, the presence of soot incandescence has been detected (Figure 4 (a) sooting combustion, (b) non-sooting combustion). For this purpose, a soot-emissivity corrected Planck's law curve is fitted to the corrected spectrum in the wavelength range of $470-585 \mathrm{~nm}$. The soot emissivity relation proposed by Musculus [25] has been used. In this spectral range, the contribution of flame chemiluminescence to the overall intensity is expected to be smallest in the available spectral range. The result of fitting procedure is a value of the apparent soot temperature at the spectrum spatial location, and the estimated brightness of soot incandescence over the complete wavelength range investigated here. The blue dashed curve in Figure 4a demonstrates the resulting Planck's law curve fit. Two criteria were devised to distinguish sooting combustion from non-sooting cases based on the Planck's law fit results. The first criterion proves the apparent soot temperature for unreasonable values: if the apparent temperature lies outside the $1500-2800 \mathrm{~K}$ range the emission was assumed not to originate from soot incandescence, therefore, the case was deemed non-sooting. The second criteria required that soot incandescence considerably contributes to the total flame luminosity at shorter wavelengths $(450 \mathrm{~nm})$ : The Planckfitted soot incandescence brightness at $450 \mathrm{~nm}$ (blue dashed line Figure $4 \mathrm{a}$ ) was compared to the total emission at $450 \mathrm{~nm}$ (black line Figure 4a). Cases, where soot incandescence did not exceed an arbitrary threshold of $50 \%$ of the total emission, were assumed to be non-sooting. These criteria were deemed to reliably determine sooting combustion by analysis of spectra with the naked eye: it was straightforward to distinguish sooting combustion spectral features from the non-sooting. 


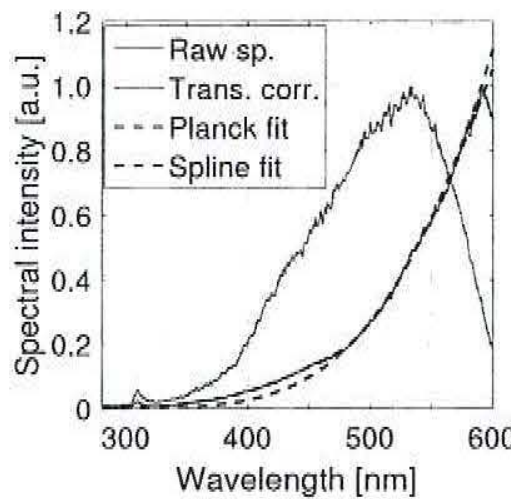

(a) Spectrum of a mildly sooting case

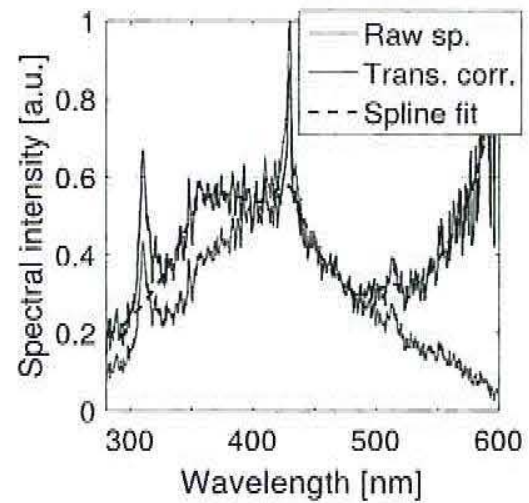

(b) Non-sooting case spectrum

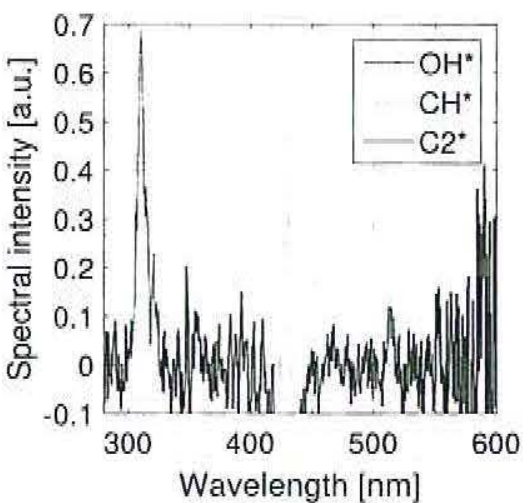

(c) Subtracted BB luminosity

Figure t: ID)-spectroseopy processing approach: (a) The raw spectrum (sp).) and transmission corrected (Trans. corr.) spectrum of at sooting combustion event. with demonstrated Planli and spline-lit curves. (b) Raw spectrum and transmission cortected spectrum of it non-sooting combustion event, with a demonstrated spline-fit result. (c) The spectrum from (b) with subtracted broadband Iuminosity.

In the sooting cases, the fitted incandescence luminosity was subtracted from the spectra. In non-sooting cases, this processing step was skipped. The remaining signal can be attributed to the flame natural luminosity. Flame luminosity (Figure 4a) shows well distinct peaks at around $310 \mathrm{~nm}, 430 \mathrm{~nm}$, and $510 \mathrm{~nm}$ on a pedestal of broadband luminosity. The separation of the $\mathrm{OH}^{*}$. $\mathrm{CH}^{*}$ and $\mathrm{C}_{2}{ }^{*}$ chemiluminescence from the broadband $(\mathrm{BB})$ luminosity follows the approach proposed in [2]. A spline fit with a long kernel (MATLAB function 'fit' using the 'SmoothingSpline' functionality with the smoothing parameter set to 0.001 ) has been used to approximate the spectrum of the background luminosity - whereas the points from the bands $305-320 \mathrm{~nm}, 423-$ $439 \mathrm{~nm}$, and $510-520 \mathrm{~nm}$ were not given to the fit function. In this way the broadband luminosity at wavelengths with overlapping narrowband species chemiluminescence was approximated. In the second step, the spline-approximated broadband luminosity has been subtracted from the spectrum (Figure $4 \mathrm{~b}$ ). The integrated signal in the spectral band of $325-350 \mathrm{~nm}$ has been used as a measure for broadband luminosity intensity. The selection of this spectra range was motivated by minimizing the interference from possible soot luminosity. The intensity of the remaining peaks (after the spline-fit subtraction) in the range of $305-320 \mathrm{~nm}, 423-439 \mathrm{~nm}$, and $510-520 \mathrm{~nm}$ has been integrated over the corresponding bands and assigned as the intensity of $\mathrm{OH}^{*}, \mathrm{CH}^{*}$ and $\mathrm{C}_{2}{ }^{*}$ chemiluminescence, respectively (Figure $4 \mathrm{~b}$ ). However, the $\mathrm{C}_{2}{ }^{*}$ chemiluminescence was too weak to be detected reliably and was not further processed.

In sooting cases, this method cannot distinguish between the soot black-body luminosity and the broadband luminosity in the upper wavelength range (above $450 \mathrm{~nm}$ ). This results in an underestimation of the broadband luminosity in sooting cases since all light emission in the range of $470-590 \mathrm{~nm}$ is considered to originate from the blackbody luminosity. In the shorter wavelength range used for broadband luminosity estimation $(325-350 \mathrm{~nm})$ this error is substantially smaller (estimates less than $20 \%$ in the most sooting considered cases) and is not expected to influence the interpretation of the results in this work.

\section{Results}

\subsection{Temporal evolution of the flame emission spectra}

The temporal evolution of the spectral emission of a non-sooting diesel $\left(\phi_{\mathrm{CH} 4}=0\right)$ and non-sooting dual-fuel $\left(\phi_{\mathrm{CH}}=0.66\right)$ combustion case at $\mathrm{T}_{\mathrm{SOI}}=810 \mathrm{~K}$ is presented in Figure 5 . In both cases, at the time of ignition, luminosity is detected across the complete spectral range acquired here. Besides the $\mathrm{OH}^{*}$ chemiluminescence emission in the range of $305-320 \mathrm{~nm}$ also two bands of broadband luminosity are visible: A band extending from approximately $300-500 \mathrm{~nm}$, and a band extending from $500 \mathrm{~nm}$ towards longer wavelengths. In accordance with the literature, the emission in the first band was attributed to $\mathrm{CO}_{2}{ }^{*}$. $\mathrm{CHO}$, and $\mathrm{CH}_{2} \mathrm{O}^{*}$ emissions. The emission of the second band persists longer than the broadband $(\mathrm{BB})$ and $\mathrm{OH} \mathrm{H}^{*}$ luminosity. In the literature this emission is commonly attributed to the overlapping $\mathrm{H}_{2} \mathrm{O}$ vibration-rotation bands $500-$ 
$580 \mathrm{~nm}$, and the NO-O continuum $400-800 \mathrm{~nm}$ [26]. In some of the dual-fuel cycles (c.f. Figure 5 b) at a later stage, an additional emission at $589 \mathrm{~nm}$ was detected and attributed to sodium D-line emission. The sodium is believed to originate from the lubrication agent used in RCEM.

The emission of $\mathrm{CH}^{*}(430 \mathrm{~nm})$ is short-lived and was only detected in the very early phase of combustion -faintly visible for the diesel case in Figure 5a inlay. The emission of $\mathrm{CH}^{*}$ in the diesel case is also accompanied with a bright emission in the wavelength band from $300-450 \mathrm{~nm}$. Contrary to the light emitted late in the cycle, during this transient the emission in blue wavelengths is brighter than at wavelengths longer than $500 \mathrm{~nm}$. In accordance to $[7,8]$ authors attributed this to the light emitted from $\mathrm{CH}_{2} \mathrm{O}^{*}$ and $\mathrm{CHO}^{*}$, which are not expected to be formed after the pilot fuel is consumed. Therefore, the emission later in the cycle might be primarily duc to $\mathrm{CO}_{2}{ }^{*}$. However, no spectral features could be detected to confirm this assumption.

A very large difference in the brightness of the diesel and dual-fuel case required different color scale representation: diesel case was multiplied by a factor of 10 . The bright transient luminosity at ignition seen in the diesel case was not visible in the dual-fuel case (Figure 5b). At late stages of combustion no significant difference in the spectral footprint of the cases in Figure 5 is apparent. In the following, the analysis focuses on the dependence of $\mathrm{OH}^{*}, \mathrm{CH}^{*}$, and broadband emission (BB) on the methane equivalence ratio, charge temperature, and pilot injection duration.

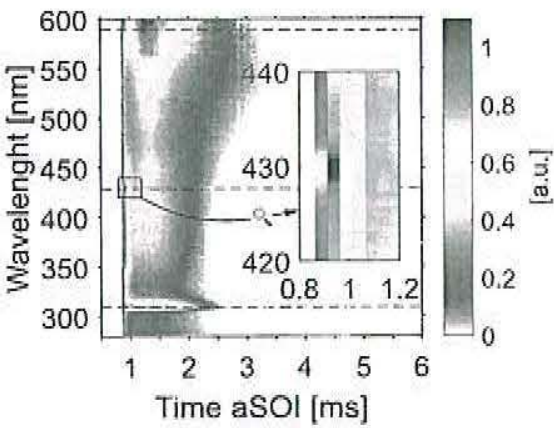

(a) $\phi_{\mathrm{CH} 4}=0$

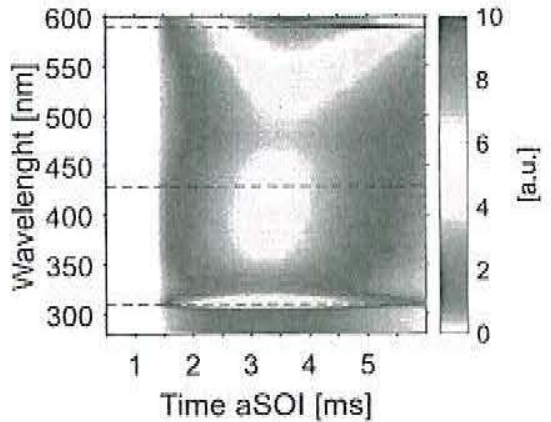

(b) $\phi_{\mathrm{CH} 4}=0.66$

Figure 5: Temporal evolution of averaged (across the injector axis) thame luminosity for (a) diesel. and (b) dual-fuel case, (onditions: $\mathrm{T}_{501}=810 \mathrm{k}$. ET $=400 \mu \mathrm{s}$. The hrightuess of the diesel cuse is multiplied by a factor of 10 to utilize the complete range of color representation. In the diesel case (a) the inlay plot shows magnified the spectrat band around 430 nm at a tinc around ignition.

The spatially ID-resolved temporal evolution of the combustion spectral intensity of $\mathrm{BB}, \mathrm{OH}^{*}$ and $\mathrm{CH}^{*}$ chemiluminescence along the injector axis for a variation of methane equivalence ratio is presented in Figure 6 . A comparison of the $\mathrm{OH}^{*}$ and $\mathrm{BB}$ chemiluminescence intensity shows only minor differences between the spatial signal distribution of both species. Only during the pilot-fuel combustion a difference between the $\mathrm{OH}^{*}$ and broadband chemiluminescence evolution was observed - the broadband signal peaks and shows a higher intensity than the $\mathrm{OH}^{*}$ signal.

The signal of $\mathrm{CH}^{*}$ shows a considerably different behavior than the $\mathrm{OH}^{*}$ and $\mathrm{BB}$. It is only present early in combustion and not detectable during the premixed flame propagation phase. It shows a high rise-rate at ignition and thus aids the detection of ignition delay. In the late phase of combustion. $\mathrm{CH}^{*}$ intensity is very weak, overlaid with bright $\mathrm{BB}$ luminosity signal. This behavior is in agreement with the literature suggesting that the $\mathrm{CH}^{*}$ is formed during the oxidation of $\mathrm{C}_{2}$ and $\mathrm{C}_{2} \mathrm{H}$ species. In the combustion of long hydrocarbon pilot-fuel and premixed methane, considerably more $\mathrm{C}_{2}$ is expected during the combustion of pilot fuel.

The different rise rates of species chemiluminescence at ignition will have a strong influence on the measured ignition delay using a thresholding technique (as already observed in Figure 2). This is demonstrated by the dashed vertical lines in Figure 6. When detecting the ignition based on an $\mathrm{OH}^{*}$ imaging thresholding approach, the slow $\mathrm{OH}$ signal rise rate at ignition might lead to an imprecise ignition delay detection, depending on the system sensitivity and the selected threshold level. This might be especially critical in dual-fuel cases where a very slow rise of the $\mathrm{OH}^{*}$ signal after the ignition has been observed. On the 
other hand, $\mathrm{CH}^{*}$ and $\mathrm{BB}$ signals show a faster rise rate at ignition and appear to enable a more precise ignition delay detection. This will be further assessed in the discussion section.

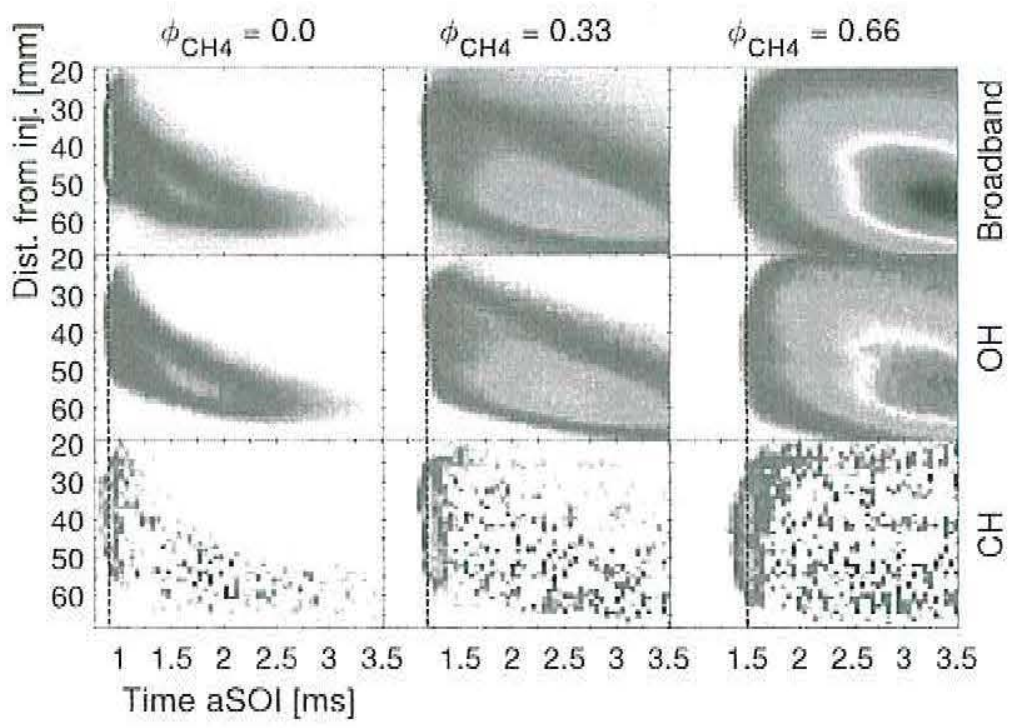

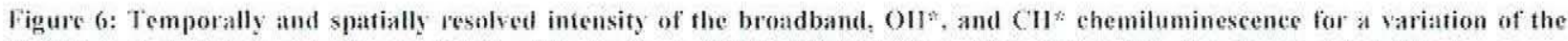
background methance equivalenee ratio, Conditions: Tsol $=810 \mathrm{k}$, Pilot injection: ET $=400 \mu$ s, Injection from top to hottom.

Figure 7 extends the analysis of the temporal species chemiluminescence evolution to a variation of charge and pilot-injection conditions. The evolution of $\mathrm{CH}^{*}, \mathrm{OH}^{*}$, and $\mathrm{BB}$-chemiluminescence intensities for an extensive variation of background methane equivalence ratio, charge temperature, injection duration, and simulated exhaust gas recirculation (EGR) is presented.

The duration of $\mathrm{CH}^{*}$ emission moderately increases with the addition of methane into the background mixture. This implies a prolonged duration of the pilot-fuel burning. However, the injection duration does not show a significant influence on the duration of $\mathrm{CH}^{*}$ signal. This also applies to $\phi_{\mathrm{CH} 4}=0$ cases with reduced charge oxygen content (bottom row, Figure 7), while to the contrary, a combination of reduced oxygen and methane addition considerably increases the duration of the $\mathrm{CH}^{*}$ emission, indicating prolonged pilot-fucl combustion.

For all variation of conditions in this study, a considerable increase of $\mathrm{OH}^{*}$ signal with the addition of methane has been observed. Focusing first on the $\phi_{\mathrm{CH}_{4}}$ variation at $\mathrm{T}_{\mathrm{SOl}}=810 \mathrm{~K}$ and $\mathrm{ET}=400 \mu \mathrm{s}$ (upper row), the diesel case shows a fast rise of $\mathrm{OH}^{*}$ signal at ignition, followed by a plateau for $1 \mathrm{~ms}$ and consequent signal decrease. With increasing $\phi_{\mathrm{CH}}$, the $\mathrm{OH}^{*}$ signal rises later (longer ID) and shows lower rise rates. Nevertheless, following the initial faster rise, the signal keeps slowly rising for $1-3 \mathrm{~ms}$ depending on the $\phi_{\mathrm{CH} 4}$ and drops considerably later. As already observed above, a several times higher peak emission of $\mathrm{OH}^{*}$ is detected with increasing $\phi_{\mathrm{CH} 4}$. This influence is especially pronounced under the $T_{\text {sol }}=770 \mathrm{~K}$ conditions and for short injections. For those lower $\mathrm{T}_{\mathrm{SOI}}$ cases (Figure 7. $2^{\text {nd }}$ row). with $\phi_{\mathrm{CH} \text { 4 }}=0$, the maximal equivalence ratio of pilot fuel rapidly leans-out, leading to a rapid decrease of $\mathrm{OH}^{*}$ brightness. With the addition of methane, the methane and pilot-fuel combination form long persisting zones with close to stoichiometric conditions. This is aligned with the longer persistence of the high $\mathrm{OH}^{*}$ signal observed in the spectral footprint.

At late stages after ignition, $\mathrm{OH}^{*}$ and $\mathrm{BB}$ signals show a very similar temporal evolution as already observed in Figure 6 . This applies to all variations in this study. Nevertheless, significant differences between the brightness of $\mathrm{OH}^{*}$ and $\mathrm{BB}$ were detected during the pilot-fuel burning period. with a steeper rise of BB emission at ignition. These results suggest BB chemiluminescence to be a better marker of the HRR during the pilot-combustion phase than the $\mathrm{OH}^{*}$ signal. The differences in the rise rate become pronounced at higher $\phi_{\mathrm{CH} 4}$ concentrations. 
In case of reduced charge-oxygen-concentration, a substantial reduction of all chemiluminescence intensities has been observed. For $15 \% \mathrm{O}_{2}$, in comparison to $21 \% \mathrm{O}_{2}$ at $\mathrm{T}_{501}=770 \mathrm{~K}$ (similar ignition delays), about two times lower $\mathrm{CH}^{*}$ intensity has been observed. $\mathrm{OH}^{*}$ and broadband luminosity are even more influenced: about a factor 4 lower $\mathrm{OH}^{*}$, and factor of 2 lower $\mathrm{BB}$ signals were observed in the diesel-case. With the addition of methane at $15 \% \mathrm{O}_{2}$, the peak $\mathrm{OH}^{*}$, and $\mathrm{BB}$ luminosity do not increase like for $21 \% \mathrm{O}_{2}$. Therefore, at $\phi_{\mathrm{CH} 4}=0.59$, going from $15 \% \mathrm{O}_{2}$ to $21 \% \mathrm{O}_{2}$, the flame brightness for both, $\mathrm{OH}^{+}$and $\mathrm{BB}$ chemiluminescence increases by a factor of about 30 . This was attributed to the decreased adiabatic flame temperature at reduced charge oxygen content.

Often reported correlations of $\mathrm{CH}^{*}$, or $\mathrm{CH}^{*} / \mathrm{OH}^{*}$ ratio, to the combustion equivalence ratio obviously do not apply in these cases. Moreover, no correlation of the cumulative $\mathrm{CH}^{*}$ emission to the total pilot-fuel quantity has been observed. On the other hand, the peak $\mathrm{CH}^{*}$ intensity seems to increase with rising $\mathrm{T}_{\text {sol, }}$ and slightly decreases with higher methane content: up to $30 \%$ of $\mathrm{CH}^{*}$ signal decrease was observed with a methane concentration of $\phi_{\mathrm{CH}}=0.66$. This complex dependence of $\mathrm{CH}^{*}$ luminosity on the charge parameters renders any quantification based on $\mathrm{CH}^{*}$ impossible.

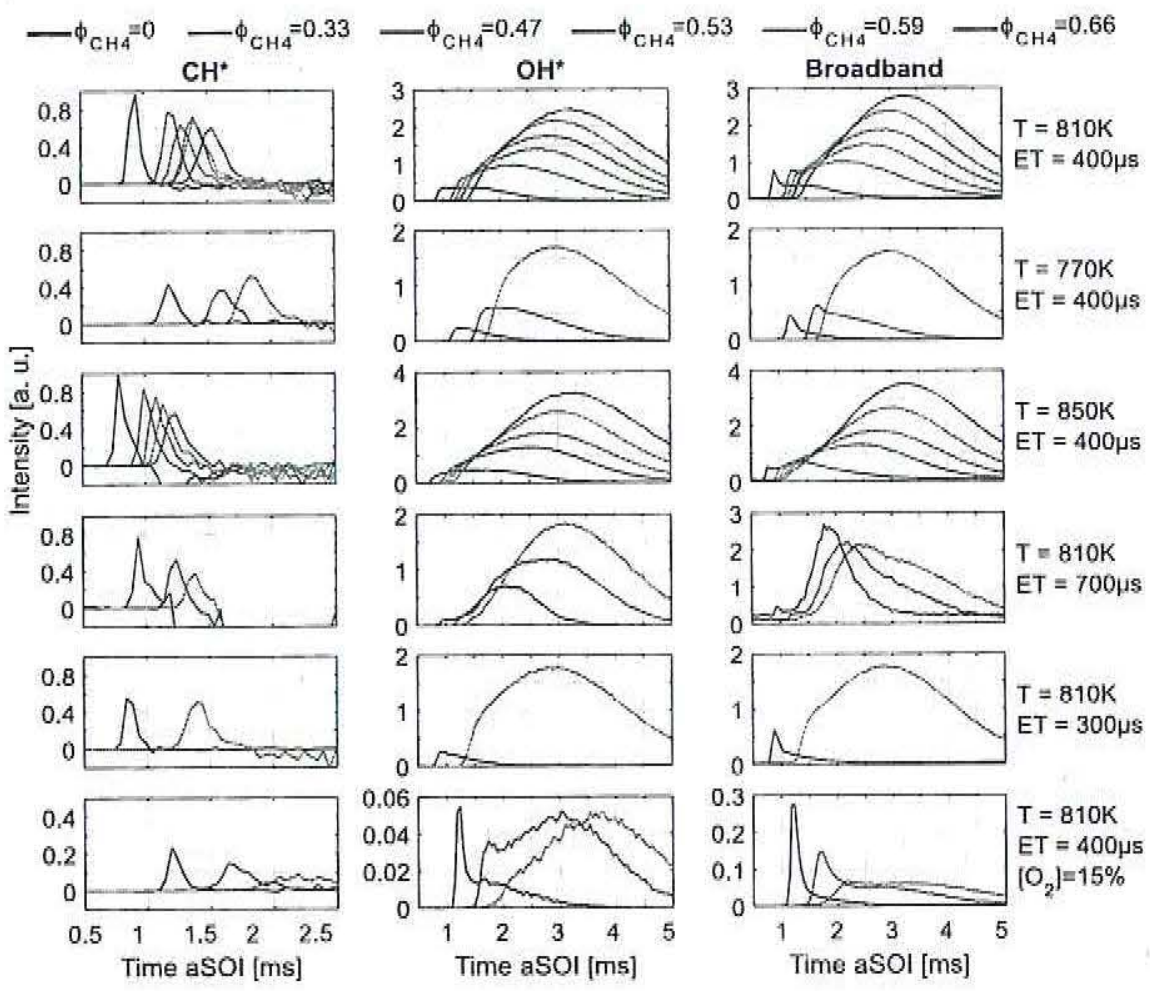

Figure 7: Fvolution of $\mathrm{CH}^{*}$, OH*, and BB luminosity for a variation of $\phi_{\mathrm{CH}}$. $\mathrm{T}_{\mathrm{SO}}$, injection $\mathrm{ET}$ and charge oxygen content. Line color marks the $\phi_{\text {cH. }}$.

\section{Discussion}

The discussion section focuses primarily on the implications of the observed spectral features for the evaluation of dual-fuel combustion natural luminosity imaging. It has been already established in the results section that the measurement of BB signal is, in general, more reliable to detect ignition than $\mathrm{OH}^{*}$, due to the steeper rise rate of $\mathrm{BB}$ signal at ignition. Furthermore, the $\mathrm{BB}$ emission spectra overlap with the emission bands of $\mathrm{OH}^{*}$ and $\mathrm{CH}^{*}$. Therefore, conventional bandpass filter imaging of $\mathrm{OH}^{*}$ and $\mathrm{CH}^{*}$ might primarily detect $\mathrm{BB}$ luminosity instead of the targeted species. 
Figure 8 presents the temporal evolution of the percentage of $\mathrm{OH}^{*}$ and $\mathrm{CH}^{*}$ contribution to the overall signal passing a bandpass filter for corresponding species detection. The heat release rate (HRR, bottom axes) is plotted for reference. This processing follows the analysis proposed by Najafabadi et al. |2]: ideal $\mathrm{OH}^{*}$ and $\mathrm{CH}^{*}$ bandpass filters transmitting in the wavelength bands of $305-320 \mathrm{~nm}$ and $425-435 \mathrm{~nm}$ were assumed for $\mathrm{OH}^{*}$ and $\mathrm{CH}^{*}$, respectively. The portion of the luminosity originating from $\mathrm{BB}$ chemiluminescence was separated from the narrow-band $\mathrm{OH}^{*}$ and $\mathrm{CH}^{*}$ emission based on spline fitting (section 2.4).

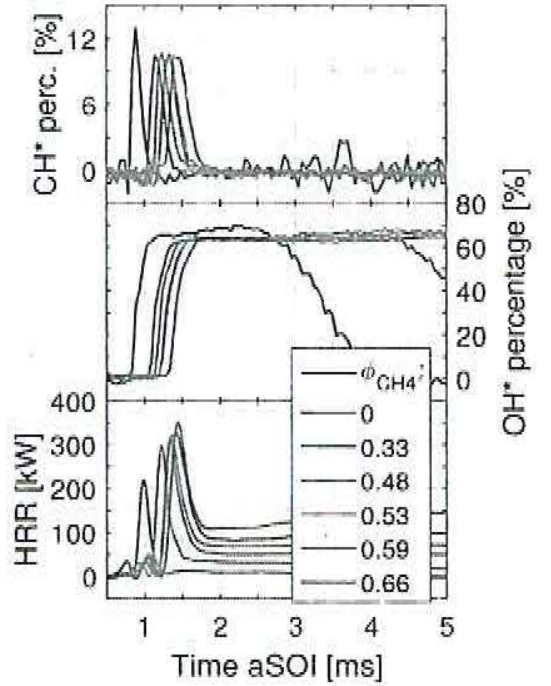

(a) $\phi_{\mathrm{CH}}$ variation, $\mathrm{ET}=400 \mu \mathrm{s}$

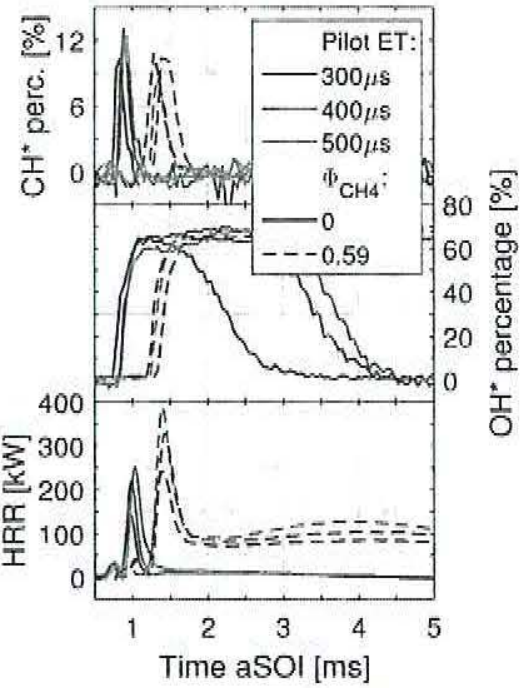

(b) $\phi_{\mathrm{CH}_{4}}$ and ET variation

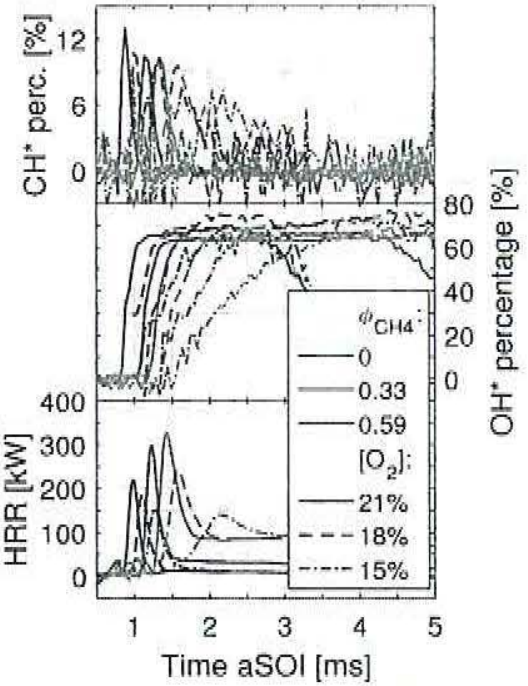

(c) $\phi_{\mathrm{CH} 4}$ and EGR variation

ligure 8: Temporal evolution of the contribution of the narrow-band $\mathrm{CI}^{*}$ (upper ases), and Oif* (middle axes) chemiluminescence to the overall luminosily emitted in the speciral hands used for $O \mathrm{H}^{*}$ and $\mathrm{CH}^{*}$ chemiluminesence detection. The HRR (botion axes) is plotted for reference. Variztions: (a) $\phi_{\mathrm{CH}}$ variation, (b) $\phi_{\mathrm{CH}}$ and FT variation, and (c) $\phi_{\mathrm{C}}$ and EGR variation.

In the literature a strong dependence of the $\mathrm{CH}^{*}$ and $\mathrm{OH}^{*}$ contribution on the level of premixed-ness in partially-premixed compression ignition combustion ivas observed [2]: only $\mathrm{BB}$ luminosity (no $\mathrm{OH}^{*}$ or $\mathrm{CH}^{*}$ ) was observed for fully premixed combustion of heptane $(\phi$ up to approximately 0.40$)$. In [2], for conditions with higher mixture stratification leading to a considerable portion of diffusion combustion, narrow-band species luminosity contributing up to $50 \%$ for $\mathrm{OH}^{*}$, and up to $15 \%$ for $\mathrm{CH}^{*}$, in the corresponding wavelength bands, were reported. Indeed, similar maximum values of the narrow-band species contributions were observed in the present study - peak values in the range of $60-70 \% \mathrm{OH}^{*}$ contribution and $10-13 \% \mathrm{CH}^{*}$ contribution were observed for all investigated conditions. This is expected since the dual-fuel combustion exhibits a considerable level of mixing inhomogeneity and higher equivalence ratios than investigated in [2].

It is interesting to compare the temporal evolution of the narrowband chemiluminescence contribution to the filtered signal. Analyzing the $\phi_{\mathrm{CH} 4}$ variation (Figure 8), a good agreement of the $\mathrm{CH}^{*}$ contribution with peak HRR is observed: the fast rise of $\mathrm{CH}^{*}$ portion at ignition and disappearance of the signal after the pilot-fuel is consumed during the peak HRR. This is in agreement with the conclusion that $\mathrm{CH}^{*}$ emission only occurs during the pilot-fucl combustion. On the contrary, the portion of $\mathrm{OH}^{*}$ starts to increase atter ignition and reaches a steady level of about $65 \%$ only after the pilot-fuel is consumed. This level of $\mathrm{OH}^{*}$ contribution remains at a plateau level for several milliseconds atter the peak HRR and begins to decrease very late in the cycle when the total flame brightness rapidly decreases.

The temporal evolution of species contribution to luminosity was found mostly insensitive to injection duration and therefore insensitive to the pilot-fuel mixture fraction at ignition (Figure 8b). Despite the four times larger fuel mass in case of the longest injection, maximal $\mathrm{CH}^{*}$ contribution remains constant at about $12 \%$ of all luminosity in the $430 \mathrm{~nm}$ band. The same was also observed in the dual-fuel case (dashed lines, different ETs). Nevertheless, a slightly lower peak $\mathrm{CH}^{*}$ contribution of 
$10 \%$ was reached. Similarly, also $\mathrm{OH}^{*}$ again rises to a plateau value of $65 \%$ which is reached after the pilot-fuel is burnt. The contribution of $\mathrm{OH}^{*}$ starts to deviate from this plateau only late in the cycle when the mixture considerably leans out.

A more substantial dependence of $\mathrm{CH}^{*}$ and $\mathrm{OH}^{*}$ contributions on $\phi_{\mathrm{CH} 4}$ was observed only in those cases with reduced charge oxygen concentration (Figure $8 \mathrm{c}$ ). Reduced peak $\mathrm{CH}^{*}$ contributions were observed at lower charge $\mathrm{O}_{2}$ (dashed and dot-dashed lines) as well as with increasing $\phi_{\mathrm{CH}_{4}}$. This is most probably due to slower pilot-fuel combustion (implied by longer $\mathrm{CH}^{*}$ signal persistence) leading to a simultaneous luminosity of already burnt and burning pilot-fuel zones. In addition, the evolution of $\mathrm{OH}^{*}$ contribution appears to be dependent on pilot-fuel burning duration. For all $\mathrm{O}_{2}$ contents, the same plateau level of $\mathrm{OH}^{*}$ contribution is achieved - however, considerably later for lower charge $\mathrm{O}_{2}$, corresponding to the time when $\mathrm{CH}^{*}$ contribution decreases.

Overall, this analysis confirms the implications for natural-luminosity imaging evaluation stated above. At ignition, the BB luminosity mostly dominates the signal in $\mathrm{OH}^{*}$ spectral range. Therefore, the acquisition of $\mathrm{BB}$ luminosity is preferred for the detection of ignition. This influence has to be accounted particularly also for validation CFD simulations employing an $\mathrm{OH}^{*}$ chemiluminescence chemical mechanism - during the pilot-fuel burning considerable differences to the experimental data might be observed since before the pilot-fucl is burnt the camera acquires mostly BB luminosity. Furthermore, this data shows that simple $\mathrm{CH}^{*}$ chemiluminescence imaging in the $430 \mathrm{~nm}$ band mostly captures other species than $\mathrm{CH}^{*}$ (Figure 8 ). Simultaneous imaging with a second camera in an adjacent wavelength band could be used to subtract the BB luminosity. Nevertheless, this would require precise calibration and possibly lead to noisy data.

The observed plateau value of $\mathrm{OH}^{*}$ contribution in all variations might indicate that this spectral emission originates from the burnt zones with a similar composition. This would be in agreement with the $\mathrm{OH}^{*}$ and $\mathrm{CO}_{2}{ }^{*}$ mechanisms, which predict persistent chemiluminescence from the hot burnt zones with the highest intensity at around stoichiometric conditions and a rapid drop of intensity at fuel richer/leaner conditions. The observed temporal evolution of the chemiluminescence emission is explained by this assumption as well, further confirmed by plotting the temporal evolution of the Abel-inverted $\mathrm{OH}^{*}$ chemiluminescence images for a variation of $\phi_{\mathrm{CH} 4}$ (Figure 9). Abel inversion transforms the line-of-sight images to crosssection images based on the axial symmetry assumption. These images were obtained by ensemble-averaging over ten experimental repetitions followed by a Fourier-transform based inverse Abel-1ransformation method proposed by Pretzler [27]. Such transformation minimizes the noise common with the simpler Abel-inversion methods.

The diesel case (Figure 9, upper panels) after ignition shows a typical diesel lifted-flame two-branch $0 \mathrm{H}^{*}$ distribution [28]. The conditions at the spray axis are believed to be too rich to produce chemiluminescence. Some time after the end of injection (EOI) the two flame branches merge (image at $0.9 \mathrm{~ms}$ ) as the EOI entrainment wave proceeds to reduce the pilot-fiel concentration upstream of the spray tip. At the spray tip, the mixture is still fuel-rich, thus resulting in a lower emission from the core of the spray. As the EOI entrainment further proceeds. the fuel-mixture continuously leans out leading to a recession of the $\mathrm{OH}^{*}$ from upstream to the tip of the spray. This results in a horseshoe shape of the emission due to the spray-tip vortex. 

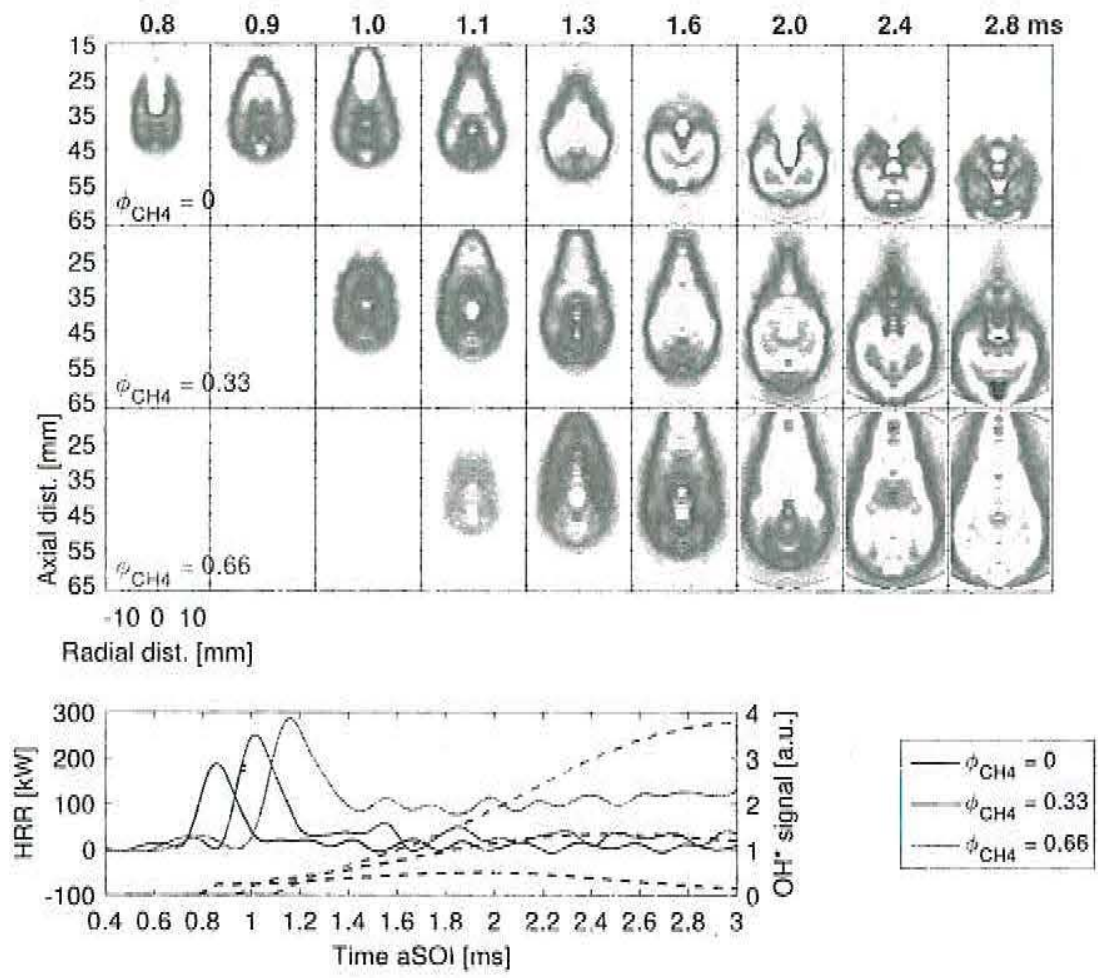

Figure 9: Temporal exolution of the Abel-inverted $0 H^{*}$ images for variation of $\phi_{\text {cat }}$. Conditions: Tsol $=850 \mathrm{k}$, Li $=400 \mu \mathrm{s}$. The hottom plot shows the evolution af the HRR (full line), and field-of-view intenrated OH* imaging signal (dashed). (ircles indicate the time instants of the image panels above.

The dual-fuel cases (Figure 9, middle and bottom rows) show a different evolution of the $\mathrm{OH}^{*}$ emission. Due to the premixed methane, a longer persistence of the $\mathrm{OH}^{*}$ emission in the wake of the spray is observed. Similarly, it also takes longer for the spray tip to lean-out. Overall, this results in large spray-plume volumes with close-to stoichiometric conditions, persisting long after the end-of-injection. This also explains the decoupled HRR rate and $\mathrm{OH}^{*}$ emission (Figure 9, bottom plot). Premixed flame propagation is barely visible on $\mathrm{OH}^{*}$ images due to the lean $\phi_{\mathrm{CH}}$ investigated in this study. Nevertheless, the overall heat release increases considerably due to the increased pilot-fuel quantity.

The findings imply a too low coupling between the $\mathrm{OH}^{*}$ and HRR for any practical application. In other words, under dualfuel engines conditions, the natural luminosity cannot be taken as a measure for the local HRR or HRR location as commonly done in $\mathrm{HCCl} / \mathrm{PCCl}$ combustion [2,11]. Furthermore, the vast range of different signal intensities originating from different areas of the combustion chamber requires a high camera dynamic range to resolve both, the premixed and pilot-fuel regions. Under some conditions, light reflections trom luminous premixed regions might exhibit higher intensities than the premixed flame propagation brightness.

\section{Conclusions}

The spectral lootprint of diesel and dual-fucl combustion was investigated ID-resolved along the injector axis using a spectrograph coupled to an intensitied high-speed camera. In summary, the study revealed three primary chemiluminescence sources in both, diesel and dual-fuel combustion: $\mathrm{OH}^{*} . \mathrm{CH}^{*}$ and broadband (BB) chemiluminescence. In the bandpass around $310 \mathrm{~nm}$ used for $\mathrm{OH}^{*}$ imaging, about $60 \%$ of the luminosity originates from $\mathrm{OH}^{*}$. BB chemiluminescence (attributed mostly to $\mathrm{CHO}^{*}, \mathrm{CH}_{2} \mathrm{O}^{*}$, and $\mathrm{CO}_{2}{ }^{*}$ ) was identified as the source of the remaining signal. At late stages of combustion. the $\mathrm{BB}$ luminosity follows similar temporal and spatial evolution as $\mathrm{OH}^{*}$. Nevertheless, at early stages during the pilot-fuel burning 
the temporal evolutions of $\mathrm{OH}^{*}$ and $\mathrm{BB}$ chemiluminescence were different. In this stage, even the emission at $310 \mathrm{~nm}$ is dominated by the $\mathrm{BB}$ luminosity. Both emissions onset simultaneously at ignition and therefore do not interfere with the ignition delay detections. The emission of the $\mathrm{CH}^{*}$ radical is a good tracer for the combustion of the pilot-fuel. However, due to the strong $\mathrm{BB}$ luminosity interference, it is challenging to detect $\mathrm{CH}^{*}$ using bandpass-filtered imaging - an acquisition using a spectrograph might be required.

Based on the analysis of experimental data the following conclusions and implications for the evaluation of natural-luminosity images can be stated:

- $\mathrm{OH}^{*}, \mathrm{CH}^{*}$ and $\mathrm{BB}$ luminosity show simultaneous onset at ignition and therefore equally qualify as a tracer for the determination of the ignition delay (ID). Integrated over the spectral domain the BB luminosity is the most intense. Furthermore, at ignition, the BB luminosity shows the steepest rise and can be therefore recommended for the future investigations of ID.

- The rise rate of luminosity at ignition decreases considerably with higher $\phi_{\mathrm{CH} 4}$ and with decreasing charge oxygen content. Large range of $\mathrm{OH}^{*} / \mathrm{BB}^{*}$ intensity from ignition to late combustion stages poses a substantial problem due to the limited detector dynamic range and sensitivity. It is therefore imperative to use the lowest possible threshold when detecting ID based on $\mathrm{OH}^{*} / \mathrm{BB}^{*}$ images in order to avoid over-prediction. If the sensitivity of the acquisition system is insufficient, the ignition delay might be considerably over-predicted,

- During the pilot-fuel burning, the light emission around $310 \mathrm{~nm}$ is dominated by the BB chemiluminescence. Therefore caution is needed when comparing the $\mathrm{OH}^{*}$ temporal evolution with simulations considering $\mathrm{OH}^{*}$ mechanism only.

- Commonly used $\mathrm{CH}^{*}$ detection using $10 \mathrm{~nm} \mathrm{FWHM}$ bandpass filter centered at $430 \mathrm{~nm}$ fails to distinguish the weak $\mathrm{CH}^{*}$ emission from the broadband luminosity. Both, in the diesel and dual-fuel cases, less than $13 \%$ of the filtered light originates from $\mathrm{CH}^{*}$. Spectroscopic and/or two-wavelength detection would be needed to separate the $\mathrm{CH}^{*}$ from the BB luminosity.

- Burned regions with close-to stoichiometric conditions dominate the flame emission at late stages of combustion. Especially at lean $\phi_{\mathrm{CH} 4}$ considerably more than an order of magnitude lower brightness is expected from the premixed flame regions. This explains the observed temporal evolution of $\mathrm{OH}^{*}$ being decoupled from the HRR and poses a challenge for the detection of premixed burning zones.

\section{Acknowledgements}

Financial support from CCEM (project \#803 "ScheDual") and the Swiss Federal Office of Energy (grant SI/50112.3-01) is gratefully acknowledged.

\section{References}

1. Pastor JV, Garcia-Oliver JM, García A, Micó C, Durrett R (2013) A spectroscopy study of gasoline partially premixed compression ignition spark assisted combustion. Applied Energy 104:568-575. doi:hitip;/dx.doi.org/10.1016/1.apenergy.2012.11.030

2. Najafabadi MI, Egelmeers L, Somers B. Deen N, Johansson B, Dam N (2017) The influence of charge stratification on the spectral signature of partially premixed combustion in a light-duty optical engine. Applied Physics B 123 . doi:http://dx, doi.org/10.1007/s00340-017-6688-9

3. Hwang W, Dec J, Sjöberg M (2008) Spectroscopic and chemical-kinetic analysis of the phases of HCCl autoignition and combustion for single- and two-stage ignition fuels. Combustion and Flame 154 (3):387-409. doi:ht1:://dx.doi.org/10.1016/1.combustflame.2008.03.019

4. Kim B, Kaneko M, Ikeda Y, Nakajima T (2002) Detailed spectral analysis of the process of HCCI combustion. Proceedings of the Combustion Institute 29 (1):671-677

5. Desantes JM, Garcia-Oliver IM, Vera-Tudela W, López-Pintor D, Schneider B, Boulouchos K (2016) Study of the autoignition phenomenon of PRFs under HCCl conditions in a RCEM by means of spectroscopy. Applied Energy 179:389-400. doi:hl1p://dx.doi.org/10.1016/1.apenergy.2016.06.134 
6. Augusta R, Foster DE, Ghandhi JB, Eng J, Najt PM (2006) Chemiluminescence measurements of homogeneous charge compression ignition (HCCl) combustion. SAE Technical Paper 2006-01-1520. doi:https://doi.org/10.4271/2006-01-1520 7. Mancaruso E, Vaglieco BM (2011) Spectroscopic measurements of premixed combustion in diesel engine. Fuel 90 (2):511= 520. doi:http://dx.doi.org/10.1016/j.fuel.2010.09.052

8. Mancaruso E, Vaglieco BM (2015) Spectroscopic analysis of the phases of premixed combustion in a compression ignition engine fuelled with diesel and ethanol. Applied Energy 143:164-175, doi;http://dx, doi,org/10.1016/i,apenergy,2015.01.031

9. Tang Q, Liu H, Yao M (2017) Simultaneous Measurement of Natural Flame Luminosity and Emission Spectra in a RCCI Engine under Different Fuel Stratification Degrees. SAE International Journal of Engines 10 (3). doi:10.4271/2017-01-0714 10. Bozkurt M, Fikri M, Schulz C (2012) Investigation of the kinetics of $\mathrm{OH} *$ and $\mathrm{CH}$ * chemiluminescence in hydrocarbon oxidation behind reflected shock waves. Applied Physics B 107 (3):515-527. doi:http://dx.doi.org/10.1007/s00340-(0)12-5012-y 11. Sardeshmukh S. Bedard M. Anderson W (2017) The use of $\mathrm{OH}^{*}$ and $\mathrm{CH}^{*}$ as heat release markers in combustion dynamics. International Journal of Spray and Combustion Dynamics 9 $(4): 409-423$. doi:http://dx.doi.org/10.1177/1756827717718483

12. Gaydon AG (1974) The Spectroscopy of Flames. Springer Netherlands, Dordrecht

13. Kopp M. Brower M, Mathieu O. Petersen E, Guthe F (2012) CO2 chemiluminescence study at low and elevated pressures. Applied Physics B 107 (3):529-538. doi:htp://dx.doi.org/10.1007/s00340-012-5051-4

14. Kopp MM, Mathieu O, Petersen EL (2015) Rate Determination of the CO2 Chemiluminescence Reaction $\mathrm{CO}+\mathrm{O}+\mathrm{M} \rightleftharpoons$ $\mathrm{CO}^{*}{ }^{*}+\mathrm{M}$ : RATE DETERMINATION OF THE CO2* CHEMILUMINESCENCE REACTION. International Journal of Chemical Kinetics 47 (1):50-72. doi:http://dx.doi.org/10.1002/kin.20892

15. Hall JM, Petersen EL (2006) An optimized kinetics model for OH chemiluminescence at high temperatures and atmospheric pressures. International Journal of Chemical Kinetics 38 (12):714-724, doi:http://dx,doi,org/10.1002/kin.20196 16. Srna A, Bolla M, Wright YM, Herrmann K, Bombach R, Pandurangi SS, Boulouchos K, Bruneaux G (2018) Effect of methane on pilot-fuel auto-ignition in dual-fuel engines. Proceedings of the Combustion Institute 37. doi:http://dx.doi.org/10.1016/i.proci.2018.06.177

17. Srna A, Bruneaux G, von Rotz B, Bombach R, Herrmann K, Boulouchos K (2018) Optical Investigation of Sooting Propensity of $n$-Dodecane Pilot/Lean-Premixed Methane Dual-Fuel Combustion in a Rapid Compression-Expansion Machine. SAE Technical Paper 2018-01-0258. doi:http:i dx.doi.org/10.4271/2018-(01-(0258

18. Schlatter S, Schneider B, Wright YM, Boulouchos K (2013) Comparative Study of lgnition Systems for Lean Burn Gas Engines in an Opticaliy Accessible Rapid Compression Expansion Machine. SAE Technical Paper 2013-24-0112. doi:http://dx.doi,org/10.4271/2013-24-0112

19. Schlatter S, Schneider B. Wright YM. Boulouchos K (2016) N-heptane micro pilot assisted methane combustion in a Rapid Compression Expansion Machine. Fuel 179:339-352. doi:http://dx.doi.org/10.1016/1.fuel.2016.03.006

20. Rochussen J, Kirchen P (2018) Characterization of reaction zone growth in an optically accessible heavy-duty diesel/methane dual-fuel engine. International Journal of Engine Research:In press, 2019. doi:http://dx.doi.org/10.1177/1468087418756538

21. Ahmad Z. Aryal J. Ranta O. Kaario O. Vuorinen V. Larmi M (2018) An Optical Characterization of Dual-Fuel Combustion in a Heavy-Duty Diesel Engine. SAE Technical Paper 2018-01-0252, doi;http://dx.doi,org/10,4271/2018-01-(0252 22. Skeen SA, Manin J, Pickett LM (2015) Simultaneous formaldehyde PLIF and high-speed schlieren imaging for ignition visualization in high-pressure spray flames. Proceedings of the Combustion Institute 35:3167-3174. doi:http://dx.doi.org/10.1016/i.proci.2014.06.040

23. Kammermann T. Koch J. Wright YM, Soltic P, Boulouchos K (2017) Generation of Turbulence in a RCEM towards Engine Relevant Conditions for Premixed Combustion Based on CFD and PIV Investigations. SAE International Journal of Engines 10 (4). doi:http://dx.doi.org/10.4271/2017-24-0043

24. Schlatter S, Schneider B, Wright Y, Boulouchos K (2012) Experimental Study of lgnition and Combustion Characteristics of a Diesel Pilot Spray in a Lean Premixed Methane/Air Charge using a Rapid Compression Expansion Machine. SAE Technical Paper 2012-01-0825. doi:http://dx.doi.ore/10.4271/2012-01-0825

25. Musculus MPB (2005) Measurements of the Influence of Soot Radiation on In-Cylinder Temperatures and Exhaust NOx in a Heavy-Duty DI Diesel Engine. SAE Technical Paper 2005-01-0925, doi:http://dx,doi,org/10,4271/2005-01-0925

26. Iijima A, Shoji H (2007) A Study of HCCI Combustion Characteristics Using Spectroscopic Techniques. SAE Technical Paper 2007-01-1886. doi: 10.4271/2007-01-1886

27. Pretzler (i (1991) A New Method for Numerical Abel-Inversion. Zeitschrift fur Naturforschung - Section A Journal of Physical Sciences 46 (7):639-641. doi:http://dx.doi.org/10.1515/7ni=1991-0715

28. Maes N, Meijer M, Dam N, Somers B. Baya Toda H. Bruneaux G. Skeen SA. Pickell LM. Manin J (2016) Characterization of Spray A flame structure for parametric variations in ECN constant-volume vessels using chemiluminescence and laser-induced lluorescence. Combustion and Flame 174:138-151. doi:http://dx.doi.org/10.1016/1.combustflame,2016.09.005 